\title{
Correspondence regarding "T-box protein 4 mutation causing pulmonary arterial hypertension and lung disease": a single-centre case series
}

\author{
To the Editor:
}

With great interest we read the article "T-box protein 4 mutation causing pulmonary arterial hypertension and lung disease" by MAURAC et al. [1]. The authors elegantly demonstrated a case of a female TBX4 mutation carrier presenting with adult-onset pulmonary arterial hypertension (PAH) in combination with bronchial and pulmonary parenchymal abnormalities which could be related to this mutation [1].

This case fits well together with the recent observation made in the French registry of heritable pulmonary hypertension (HPAH) that TBX4 mutations are frequently found in both adult and paediatric PAH cases $[2,3]$.

Here, we present data on the currently known TBX4 mutation carriers in our institute. The cohort consists of three mutation carriers without PAH, one patient with early PAH and four patients with HPAH. In all but one patient, a diagnosis of PAH was made in adulthood. Four different heterozygous variants in TBX4 were identified in the eight subjects (two families were included in the cohort). All variants were classified as "likely pathogenic" or "pathogenic", including missense mutations (subject 1,5 and 8) and frameshift mutations (subject 2, 3, 4, 6 and 7). A targeted gene panel was analysed in our cohort using next generation sequencing. Using this technique only small deletions or insertions were detected. To date, it has not been possible to determine the disease penetrance of TBX4 mutations, due to the low number of known carriers of such mutations [4].

The median age at diagnosis of PAH in our cohort was 31 (interquartile range (IQR) 39) years, while carriers without PAH had a median age of 39 (IQR 20) years. Remarkably, all patients were female and all carriers without $\mathrm{PAH}$ were male. All subjects, including the carriers without PAH, had skeletal anomalies on clinical examination, including a sandal gap in all and a small patella in one carrier without PAH and two HPAH patients. Subject demographic and clinical characteristics are shown in table 1. Two carriers without $\mathrm{PAH}$ were assessed by echocardiography alone, while six subjects underwent at least one right heart catheterisation (RHC) for diagnostic or research purposes (one carrier without PAH). The systolic pulmonary artery pressure on echocardiography was not measurable in two carriers without PAH because no tricuspid insufficiency could be measured. No other signs of PAH were noticed on echocardiography. In the six subjects in whom RHC was performed, elevated mean pulmonary artery pressures (mPAP) (median $44 \mathrm{mmHg}$, IQR $66.5 \mathrm{mmHg}$ ) and pulmonary vascular resistance indices (median $6.2 \mathrm{WU}$, IQR 15.1 WU) were demonstrated. However, only four out of six subjects met all criteria for a strict diagnosis of PAH based on the current guidelines [5]. One subject had early signs of PAH including a mPAP of $28 \mathrm{mmHg}$, but PVR did not exceed the threshold of $3 \mathrm{WU}(2.4 \mathrm{WU})$. All four HPAH patients and the early PAH patient were treated with pulmonary hypertension-targeted therapy, predominantly double combination therapy (table 1).

Noticeably, all subjects with HPAH had a medical history of asthma with a mildly reduced forced expiratory volume in $1 \mathrm{~s}$ (median $74 \%$ of predicted value, IQR $11 \%$ ). In addition, median diffusing capacity of the lung for carbon monoxide $\left(D_{\text {LCO }}\right)$ was mildly reduced $(65 \%$ of the predicted value, IQR

@ERSpublications

A single-centre case series of adult subjects with a TBX4 mutation, in whom two distinctive findings on HRCT (i.e. tracheal and bronchial diverticulosis; irregular bronchial walls) were observed http://bit. ly/2v3s7HE

Cite this article as: Jansen SMA, van den Heuvel L, Meijboom LJ, et al. Correspondence regarding "T-box protein 4 mutation causing pulmonary arterial hypertension and lung disease": a single-centre case series. Eur Respir J 2020; 55: 1902272 [https://doi.org/10.1183/13993003.02272-2019]. 


\begin{tabular}{|c|c|c|c|c|c|c|c|c|}
\hline & Subject 1 & Subject 2 & Subject 3 & Subject 4 & Subject 5 & Subject 6 & Subject 7 & Subject 8 \\
\hline Diagnosis & $\begin{array}{c}\text { Carrier without } \\
\text { PAH }\end{array}$ & $\begin{array}{c}\text { Carrier without } \\
\text { PAH }\end{array}$ & Carrier without PAH & Early PAH & HPAH & HPAH & $\mathrm{HPAH}$ & $\mathrm{HPAH}$ \\
\hline Family number & $2: 1-2$ & $1: \| 1-2$ & $1: \|-3$ & $1: \|-1$ & $2: 1-1$ & $3: 1-1$ & $1: \mid-1$ & $4: 1-1$ \\
\hline TBX4 mutation & $\begin{array}{l}\text { c.1164dup } \\
\text { p.(Arg389fs) }\end{array}$ & $\begin{array}{c}\text { c.1112del } \\
\text { p.(Pro371Leufs*8) }\end{array}$ & $\begin{array}{c}\text { c.1112del } \\
\text { p.(Pro371Leufs*8) }\end{array}$ & $\begin{array}{c}\text { c.1112del } \\
\text { p.(Pro371Leufs*8) }\end{array}$ & $\begin{array}{l}\text { c.1164dup } \\
\text { p.(Arg389fs) }\end{array}$ & $\begin{array}{c}\text { c.40_49del } \\
\text { p.(Phe14Argfs*28) }\end{array}$ & $\begin{array}{c}\text { c.1112del } \\
\text { p.(Pro371Leufs*8) }\end{array}$ & c. $916 \mathrm{G}>\mathrm{T}$ p.(Glu306*) \\
\hline \multicolumn{9}{|l|}{ Characteristics } \\
\hline Age at diagnosis years & 27 & 47 & 39 & 50 & 16 & 31 & 63 & 19 \\
\hline Gender & Male & Male & Male & Female & Female $^{\#}$ & Female & Female & Female \\
\hline NT-proBNP ng. $\mathrm{L}^{-1}$ & & 24 & 18 & 91 & 109 & 226 & 451 & 1627 \\
\hline Medical history & No & No & No & Asthma & $\begin{array}{l}\text { Asthma, colitis } \\
\text { ulcerosa }\end{array}$ & Asthma & Asthma & Asthma \\
\hline Smoking $>1$ pack-year & No & No & No & No & No & No & No & No \\
\hline Sandal Gap & Yes & Yes & Yes & Yes & Yes & Yes & Yes & Yes \\
\hline Small patella & No & Yes & No & No & Yes & No & No & Yes \\
\hline \multicolumn{9}{|l|}{ Pulmonary function test } \\
\hline $\mathrm{FEV}_{1} \%$ & 96 & 91 & 100 & 97 & 73 & 75 & 84 & 70 \\
\hline FVC $\%$ & 97 & 111 & 107 & 107 & 88 & 84 & 102 & 71 \\
\hline $\mathrm{FEV}_{1} / \mathrm{VC} \%$ & 80 & 67 & 75 & 72 & 72 & 77 & 70 & 87 \\
\hline$D_{\mathrm{LCO}} \%$ & 120 & - & 99 & 98 & 73 & 58 & 65 & 65 \\
\hline \multicolumn{9}{|l|}{ Echocardiography } \\
\hline PASP $\mathrm{mmHg}$ & No TI & No TI & 24 & No TI & 51 & 122 & 60 & 130 \\
\hline Signs of $\mathrm{PH}$ on echo & None & None & None & $\begin{array}{l}\text { Mid-systolic notch PA } \\
\text { flow }\end{array}$ & RV dilation & $\begin{array}{l}\text { Mild PE, RV hypertrophy } \\
\text { and dilation }\end{array}$ & RV hypertrophy & RV dilation \\
\hline \multicolumn{9}{|l|}{ Right heart catheterisation } \\
\hline mPAP $\mathrm{mmHg}$ & & & 20 & 28 & 45 & 91 & 43 & 97 \\
\hline Cardiac output L. $\min ^{-1}$ & & & 8.5 & 6.3 & 5.5 & 2.8 & 5.5 & 5.3 \\
\hline PVR WU & & & 0.9 & 2.4 & 6.9 & 17.9 & 5.5 & 16.9 \\
\hline Wedge pressure $\mathrm{mmHg}$ & & & 12 & 13 & 7 & 14 & 13 & 7 \\
\hline HRCT & $\begin{array}{l}\text { Sporadic tracheal } \\
\text { and bronchial } \\
\text { diverticulosis, } \\
\text { irregular } \\
\text { bronchial walls }\end{array}$ & & $\begin{array}{l}\text { Sporadic tracheal } \\
\text { and bronchial } \\
\text { diverticulosis, } \\
\text { irregular bronchial } \\
\text { walls }\end{array}$ & $\begin{array}{c}\text { Multiple tracheal and } \\
\text { bronchial } \\
\text { diverticulosis, irregular } \\
\text { bronchial walls, air } \\
\text { trapping, perifissural } \\
\text { nodules }\end{array}$ & $\begin{array}{l}\text { Multiple tracheal } \\
\text { and bronchial } \\
\text { diverticulosis, } \\
\text { irregular bronchial } \\
\text { walls, interlobular } \\
\text { septal thickening }\end{array}$ & $\begin{array}{l}\text { Multiple tracheal and } \\
\text { bronchial diverticulosis, } \\
\text { irregular bronchial } \\
\text { walls, air trapping, } \\
\text { centrilobular } \\
\text { ground-glass opacities }\end{array}$ & $\begin{array}{l}\text { Sporadic tracheal and } \\
\text { bronchial diverticulosis, } \\
\text { irregular bronchial } \\
\text { walls, air trapping, } \\
\text { small subpleural } \\
\text { nodules }\end{array}$ & $\begin{array}{l}\text { Multiple tracheal } \\
\text { and bronchial } \\
\text { diverticulosis, } \\
\text { irregular bronchial } \\
\text { walls, air trapping, } \\
\text { centrilobular } \\
\text { ground-glass } \\
\text { opacities }\end{array}$ \\
\hline PAH specific treatment & & & & ERA & ERA, PDE5-i & ERA, PDE5-i & ERA, PDE5-i & $\begin{array}{l}\text { ERA, PDE5-i, } \\
\text { prostacyclin } \\
\text { analogue }\end{array}$ \\
\hline
\end{tabular}

NT-proBNP: N-terminal pro-brain natriuretic peptide; $\mathrm{FEV}_{1}$ : forced expiratory volume in $1 \mathrm{~s}$; FVC: forced vital capacity; VC: vital capacity; $D_{\mathrm{Lco}}$ : diffusing capacity of the lungs for carbon monoxide: PASP: pulmonary artery systolic pressure; PH: pulmonary hypertension; mPAP: mean pulmonary artery pressure: PVR: pulmonary vascular resistance: HRCT: high-resolution computed tomography; PAH: pulmonary arterial hypertension; HPAH: heritable pulmonary hypertension; PA: pulmonary artery; RV: right ventricle; PE: pulmonary effusion; ERA: endothelin receptor antagonist; PDE5-i: phosphodiesterase type 5 inhibitor. ${ }^{\#}$ : at age of 25 years old start of female-to-male transition. Sporadic diverticulosis is defined as less than five protrusions, multiple diverticulosis is defined as more than five protrusions. 
FIGURE 1 Bronchial diverticulosis in a pulmonary arterial hypertension patient carrying a TBX4 mutation. Coronal image from high-resolution computed tomography with a maximal intensity projection of $2 \mathrm{~mm}$.

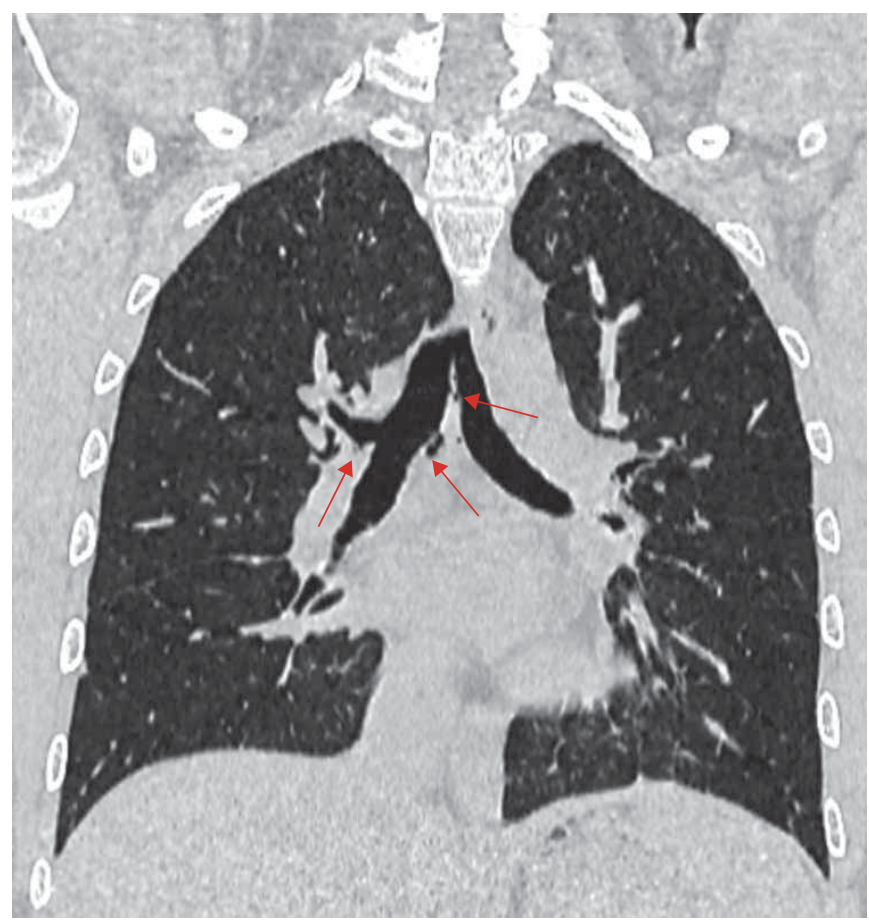

$11.2 \%)$; three out of four HPAH patients had an abnormal $D_{\mathrm{LCO}}<70 \%$. High-resolution computed tomography was performed in all subjects except one carrier without $\mathrm{PAH}$ and showed a spectrum of findings, including air trapping, interlobular septal thickening, centrilobular ground-glass opacities and small nodules. Tracheal and bronchial diverticulosis was found in all subjects, including the carriers without PAH (figure 1). In addition, all subjects showed irregular bronchial walls with changes in calibres predominantly in the (sub)segmental bronchi. Airway abnormalities were milder in carriers without PAH, but there was no relation between extent of airway abnormalities and severity of haemodynamic compromise in patients.

Overall, this small cohort of carriers without PAH and PAH patients carrying a TBX4 mutation may help to get a better understanding of HPAH. Animal studies have shown that TBX4 (in concert with TBX5) is important for lung branching and the formation of cartilage rings in the trachea. This may explain the observation that all TBX4 mutation carriers displayed tracheal diverticulosis and irregularity of the bronchial walls [6]. The lung abnormalities previously observed in TBX4 mutation carriers form a broad clinical spectrum. Neonatal patients have predominantly severe and diffuse features of growth arrest, including acinar dysplasia, while milder features of bronchial abnormalities, including interstitial remodelling, are more common in patients diagnosed post-neonatally, in childhood or as adults [1, 7-9]. Because airway abnormalities were observed in subjects with no signs of pulmonary hypertension and also because the degree of abnormalities on computed tomography was not correlated to the degree of haemodynamic compromise, it remains to be determined whether pulmonary hypertension in TBX4 mutation carriers develops as a consequence of airway abnormalities (placing this form of pulmonary hypertension in group 3 of the diagnostic classification). Alternatively, airway and vascular abnormalities in TBX4 mutation carriers may develop entirely independently.

Further studies are required to better understand phenotypic expression, penetrance (including an apparently much higher penetrance in females) and the optimal treatment approach of TBX4 associated PAH.

Samara M.A. Jansen ${ }^{1}$, Lieke van den Heuvel$^{2}$, Lilian J. Meijboom ${ }^{3}$, Suzanne I.M. Alsters ${ }^{2}$, Anton Vonk Noordegraaf $^{1}$, Arjan C. Houweling ${ }^{2}$ and Harm Jan Bogaard ${ }^{1}$

${ }^{1}$ Dept of Pulmonary Diseases, Amsterdam UMC, Vrije Universiteit Amsterdam, Amsterdam, The Netherlands. ${ }^{2}$ Dept of Genetics, Amsterdam UMC, Vrije Universiteit Amsterdam, Amsterdam, The Netherlands. ${ }^{3}$ Dept Of Radiology and Nuclear Medicine, Amsterdam UMC, Vrije Universiteit Amsterdam, Amsterdam, The Netherlands.

Correspondence: Harm Jan Bogaard, Amsterdam UMC, Vrije Universiteit Amsterdam, Dept of Pulmonology, Amsterdam Cardiovascular Sciences, De Boelelaan 1117, Amsterdam, The Netherlands.

E-mail: hj.bogaard@amsterdamumc.nl

Received: 25 Nov 2019 | Accepted after revision: 27 Jan 2020 
Conflict of interest: S.M.A. Jansen has nothing to disclose. L. van den Heuvel has nothing to disclose. L.J. Meijboom has nothing to disclose. S.I.M. Alsters has nothing to disclose. A. Vonk Noordegraaf reports personal fees for lectures from Actelion and MSD, outside the submitted work. A. Houweling has nothing to disclose. H.J. Bogaard reports grants from Actelion, Ferrer and GSK, outside the submitted work.

\section{References}

1 Maurac A, Lardenois E, Eyries M, et al. T-box protein 4 mutation causing pulmonary arterial hypertension and lung disease. Eur Respir J 2019; 54: 1900388.

2 Eyries M, Montani D, Nadaud S, et al. Widening the landscape of heritable pulmonary hypertension mutations in paediatric and adult cases. Eur Respir J 2019; 53: 1801371.

3 Graf S, Haimel M, Bleda $\mathrm{M}$, et al. Identification of rare sequence variation underlying heritable pulmonary arterial hypertension. Nat Commun 2018; 9: 1416.

4 Girerd B, Weatherald J, Montani D, et al. Heritable pulmonary hypertension: from bench to bedside. Eur Respir Rev 2017; 26: 170037.

5 Galie N, Humbert M, Vachiery JL, et al. 2015 ESC/ERS Guidelines for the diagnosis and treatment of pulmonary hypertension: The Joint Task Force for the Diagnosis and Treatment of Pulmonary Hypertension of the European Society of Cardiology (ESC) and the European Respiratory Society (ERS). Eur Respir J 2015; 46: 903-975.

6 Arora R, Metzger RJ, Papaioannou VE. Multiple roles and interactions of Tbx4 and Tbx5 in development of the respiratory system. PLoS Genet 2012; 8: e1002866.

7 Suhrie K, Pajor NM, Ahlfeld SK, et al. Neonatal lung disease associated with TBX4 mutations. J Pediatr 2019; 206: 286-292.

8 Galambos C, Mullen MP, Shieh JT, et al. Phenotype characterisation of TBX4 mutation and deletion carriers with neonatal and paediatric pulmonary hypertension. Eur Respir J 2019; 54: 1801965.

9 Szafranski P, Coban-Akdemir ZH, Rupps R, et al. Phenotypic expansion of TBX4 mutations to include acinar dysplasia of the lungs. Am J Med Genet A 2016; 170: 2440-2444. 